\title{
Signaling Mechanisms Controlling Cell Fate and Embryonic Patterning
}

\author{
Norbert Perrimon ${ }^{1,2}$, Chrysoula Pitsouli ${ }^{1,3}$, and Ben-Zion Shilo ${ }^{4}$ \\ ${ }^{1}$ Department of Genetics, Harvard Medical School, Boston, Massachusetts 02115 \\ ${ }^{2}$ Howard Hughes Medical Institute, Boston, Massachusetts 02115 \\ ${ }^{3}$ Department of Biological Sciences, University of Cyprus, 1678 Nicosia, Cyprus \\ ${ }^{4}$ Department of Molecular Genetics, Weizmann Institute of Science, Rehovot 76100, Israel \\ Correspondence: perrimon@receptor.med.harvard.edu
}

\section{SUMMARY}

During development, signaling pathways specify cell fates by activating transcriptional programs in response to extracellular signals. Extensive studies in the past 30 years have revealed that surprisingly few pathways exist to regulate developmental programs and that dysregulation of these can lead to human diseases, including cancer. Although these pathways use distinct signaling components and signaling strategies, a number of common themes have emerged regarding their organization and regulation in time and space. Examples from Drosophila, such as Notch, Hedgehog, Wingless/WNT, BMP (bone morphogenetic proteins), EGF (epidermal growth factor), and FGF (fibroblast growth factor) signaling, illustrate their abilities to act either at a short range or over a long distance, and in some instances to generate morphogen gradients that pattern fields of cells in a concentration-dependent manner. They also show how feedback loops and transcriptional cascades are part of the logic of developmental regulation.

\section{Outline}

1 Introduction

2 Embryonic patterning: Interplay between transcriptional cascades and signaling

3 Juxtacrine signaling: Notch as an example

4 Patterning by secreted paracrine factors

5 Controlling the signaling range of secreted factors
6 The logic of signaling

7 Integrating signaling pathways

8 Concluding remarks: Developmental versus physiological signaling

References

Editors: Lewis Cantley, Tony Hunter, Richard Sever, and Jeremy Thorner

Additional Perspectives on Signal Transduction available at www.cshperspectives.org

Copyright (C) 2012 Cold Spring Harbor Laboratory Press; all rights reserved; doi: 10.1101/cshperspect.a005975

Cite this article as Cold Spring Harb Perspect Biol 2012;4:a005975 
N. Perrimon et al.

\section{INTRODUCTION}

Key to multicellularity is the coordinated interaction of the various cells that make up the body. Indeed, patterning of embryos, establishment of cell type diversity, and formation of tissues and organs all rely on cell-to-cell communication during development. Thus, arguably one of the most important principles of developmental biology involves "one group of cells changing the behavior of an adjacent set of cells, causing them to change their shape, mitotic rate, or fate" (Gilbert 2000).

Classically, the ability of one group of cells to affect the fate of another is called "induction." The cells that produce the signals are referred to as "inducing cells," whereas the receiving cells are termed "responders" (Spemann and Mangold 1924). The ability of cells to respond to the inducers, referred to as "competence" (Waddington 1940), usually reflects the presence of a receptor at the top of a pathway that regulates the expression of specific transcription factors in the responding cells. The responding cells, in turn, can become inductive and change the fate of their neighbors by producing new signals, thus generating sequential inductive events that increase cell-fate diversity in tissues.

Identification and characterization of the signaling pathways involved in development has led to the surprising realization that only a few exist (Gerhart 1999; Gilbert 2000; Barolo and Posakony 2002). These fall into 11 main classes, defined by the ligand or signal transducers involved: Notch, FGF, EGF, Wnt/Wingless (Wg), Hedgehog (Hh), transforming growth factor $\beta$ (TGF $\beta$ )/BMPs, cytokine (nonreceptor tyrosine kinase JAK-STAT [signal transducers and activators of transcription] pathway), Hippo, Jun kinase (JNK), NF- $\kappa B$, and retinoic acid receptor (RAR). These pathways involve either cell-to-cell contact via surface proteins (juxtacrine signaling), or secreted diffusible growth and differentiation factors ( paracrine signaling). Among the pathways mentioned above, only two of them, Notch and Hippo, are juxtacrine, whereas the others are paracrine.

With the exception of those that release steroid hormones and retinoic acid, which cross the membrane and activate gene expression by binding directly to receptor proteins that act as transcriptional regulators, inducing cells generally produce secreted or transmembrane ligands, which in some cases require complex processing in the producing cells or the extracellular matrix. When these ligands bind to transmembrane receptors on target cells they activate a cascade of events that ultimately regulate the activity of a small number of transcription factors and/or cofactors, triggering gene-expression programs that drive the cellular changes. For example, Notch signaling (Kopan 2012) regulates CSL (for CBF1, Suppressor of Hairless, and Lag1) proteins that possess an integrase domain, receptor tyrosine kinases (RTKs) regulate ETS (erythroblast transformationspecific) transcription factors, Wnt ligands (Nusse 2012) mostly regulate the high-mobility group (HMG) box-containing TCF (T-cell factor) transcription factor, Hh proteins (Ingham 2012) regulate Gli (glioblastoma) transcription factors that have DNA-binding zinc-finger domains, and BMPs (Wrana 2012) regulate Smads (Sma- and Mad-related proteins) transcription factors. Cytokine pathways (Harrison 2012) regulate STATs, and Hippo (Hariharan 2012) regulates TAZ (for transcriptional coactivator with PDZbinding motif) proteins that contain a WW domain and a carboxy-terminal PDZ-binding motif (Table 1). In addition, many pathways activate feedback loops that modulate or terminate the incoming signal (Perrimon and McMahon 1999; Freeman 2000).

The response to signaling-pathway activation is usually complex and involves the regulation of many processes, such as control of cell fate, apoptosis, cell proliferation, cytoskeletal reorganization, cell polarity, adhesion, and cell migration. Importantly, each pathway does not specifically regulate a single biological process but can elicit diverse effects, depending on the state of the cell at the time the pathway is activated. Furthermore, because few pathways exist, there are no unique signals for induction of each cell type. Instead, the response of a given cell to a signal depends on its amplitude, duration, interactions between pathways, and integration of transcription factor effectors at promoters and enhancers of target genes. It may also be predetermined by the set of transcription factors expressed in the cell at the time the signal is received.

Here, we use specific examples, mostly taken from Drosophila, to illustrate general principles and mechanisms by which signaling pathways operate in development to specify cell fates. Thus, this is not a comprehensive review of the structures and roles of all the pathways that have been implicated in developmental processes. A number of excellent reviews elsewhere describe in detail the roles of individual pathways in development (Notch [Artavanis-Tsakonas et al. 1999; Lai 2004; Fortini 2009], FGF [Ghabrial et al. 2003; Pownall and Isaacs 2010], EGF [Shilo 2005], Wnt/Wg [Logan and Nusse 2004; MacDonald et al. 2009], Hh [Ingham and McMahon 2001; Jiang and Hui 2008], TGF 3 [Feng and Derynck 2005; Wu and Hill 2009], JAK/STAT [Hou et al. 2002; Arbouzova and Zeidler 2006], and Hippo [Pan 2007; Saucedo and Edgar 2007]).

Note also that a number of other pathways, such as those involving cadherins and integrins, are not discussed here as they are involved in permissive interactions whereby a tissue is made competent to respond and requires the proper environment to trigger the appropriate cellular changes (Gilbert 2000). We also do not discuss signaling pathways that 
Table 1. Key signaling pathways that orchestrate development-receptors, ligands, transcription factors, and outputs are shown for each

\begin{tabular}{|c|c|c|c|c|}
\hline Signaling pathway & Receptor & Ligand & Transcriptional effector & Output \\
\hline Wnt/Wg & Frizzled, dFrizzled2 & $\mathrm{Wg} / \mathrm{Wnt}$ & $\begin{array}{l}\text { Armadillo/ } \beta \text {-catenin } \\
\text { with TCF/LEF }\end{array}$ & $\begin{array}{l}\text { Patterning, growth, PCP ( } \beta \text {-catenin } \\
\text { independent })\end{array}$ \\
\hline $\mathrm{Hh}$ & Patched & $\mathrm{Hh}$ & $\mathrm{Ci} / \mathrm{Gli}$ & Patterning, growth \\
\hline TGF $\beta$ & Thickveins & Dpp/TGF $\beta$ & Smad (Mad/Medea) & Patterning, growth \\
\hline \multirow[t]{7}{*}{ RTK } & EGFR & Spitz, Gurken, Keren, Vein & Pointed/Yan & Patterning, morphogenesis \\
\hline & $\begin{array}{l}\text { FGFR (Breathless, } \\
\text { Heartless) }\end{array}$ & Branchless, Thisbe, Pyramus & Pointed/Yan & Patterning, morphogenesis, migration \\
\hline & InR & dIlp1-dIlp7 & Pointed/Yan, Foxo & Growth, metabolism, aging \\
\hline & $\begin{array}{l}\text { PDGF/VEGF receptor } \\
\text { (PVR) }\end{array}$ & Pvf1-3 & Pointed/Yan & Morphogenesis, migration \\
\hline & Torso & Trunk, PTTH & Pointed/Yan & Patterning, metamorphosis \\
\hline & dALK & Jelly belly & Pointed/Yan & Growth on starvation (CNS) \\
\hline & Sevenless & Boss & Pointed/Yan & Patterning, cell-fate specification \\
\hline Notch & Notch & Delta, Serrate & NICD with $\mathrm{Su}(\mathrm{H})$ & $\begin{array}{l}\text { Patterning, lateral inhibition, cell-fate } \\
\text { specification }\end{array}$ \\
\hline Hippo & Fat & Dachsous & Yorkie with Scalloped & Growth, PCP \\
\hline NF-кB & Toll & Spatzle & Dorsal/Dif & Patterning, innate immunity \\
\hline JAK/STAT & Domeless & Unpaired1-3 & STAT92E & Patterning, innate immunity \\
\hline JNK & Eiger/TNF & Wengen & Jun and Fos & Migration, patterning, innate immunity \\
\hline Nuclear receptors & EcRA, EcRB & Ecdysone & EcRA, EcRB with USP & Patterning, growth, metabolism \\
\hline
\end{tabular}

Abbreviations: TCF, T-cell factor; LEF, lymphoid enhancer-binding factor; PCP, planar cell polarity; TGF, transforming growth factor; RTK, receptor-tyrosine kinase; EGFR, epidermal growth factor receptor; FGFR, fibroblast growth factor receptor; PVDF, polyvinylidene difluoride; VEGFR, vascular endothelial growth factor; PTTH, prothoracicotropic hormone; CNS, central nervous system; NICD, Notch intracellular domain; STAT, signal transducer and activator of transcription; JNK, JUN kinase; TNF, tumor necrosis factor; USP, ubiquitin-specific protease.

control cellular behavior and cytoskeletal reorganizationfor example, cell migration and axonal pathfinding.

\section{EMBRYONIC PATTERNING: INTERPLAY BETWEEN TRANSCRIPTIONAL CASCADES AND SIGNALING}

Following fertilization, as embryonic development proceeds, different cell types are formed progressively. With time, cells become more and more restricted in their developmental potential, and become determined to a specific fixed fate that represents a stable change in the internal state of the cell as a result of alterations in gene expression. The gradual increase in complexity occurring during determination and subsequent differentiation involves complex combinations of transcription factors. Some of these factors are common to many cell types, whereas others are present in only specific cell types. The changes in gene expression rely in part on the activation of signaling pathways by cellcell communication. In the context of development, signaling pathways dictate developmental switches and as such are usually irreversible, pushing forward the developmental program in a ratchetlike mechanism by regulating the activity of transcription factors.

For example, patterning along the anteroposterior axis of the Drosophila embryo is initially set up by graded activity of the Bicoid transcription factor, which acts in a concentration-dependent manner to control the expression of gap genes (Fig. 1A) (St Johnston and Nusslein-Volhard 1992). These gap genes, in turn, coordinately define the domain of expression of pair-rule genes, which then define the expression of segment-polarity genes (Nusslein-Volhard and Wieschaus 1980). Although both gap and pair-rule genes encode diverse types of transcription factors, some of the segment-polarity genes, such as $h h$ and $w g$, encode signaling molecules that activate pathways that operate in positive regulatory loops, to maintain each other's expression and the induced cell fates within the embryonic segmental unit (Heemskerket al. 1991). In addition to the Bicoid patterning system, the Torso RTK pathway activates the Ras/ MAP kinase (MAPK) pathway to control the spatial expression of the Tailless and Huckebein transcription factors at the embryonic termini (Fig. 1C) (Duffy and Perrimon 1994). Finally, along the dorso-ventral axis of the embryo activation of the Toll receptor by the Spätzle ligand activates Dorsal (the fly homolog of NF- $\mathrm{KB}$ ), which regulates the expression of Twist and Snail, two transcription factors that control mesoderm development, while repressing other genes, such as rhomboid and sog (Fig. 1B) (Levine 2008).

Hierarchies of transcription factor expression that progressively dictate distinct cell fates are common at later developmental stages in a variety of tissues. For example, 
N. Perrimon et al.

A

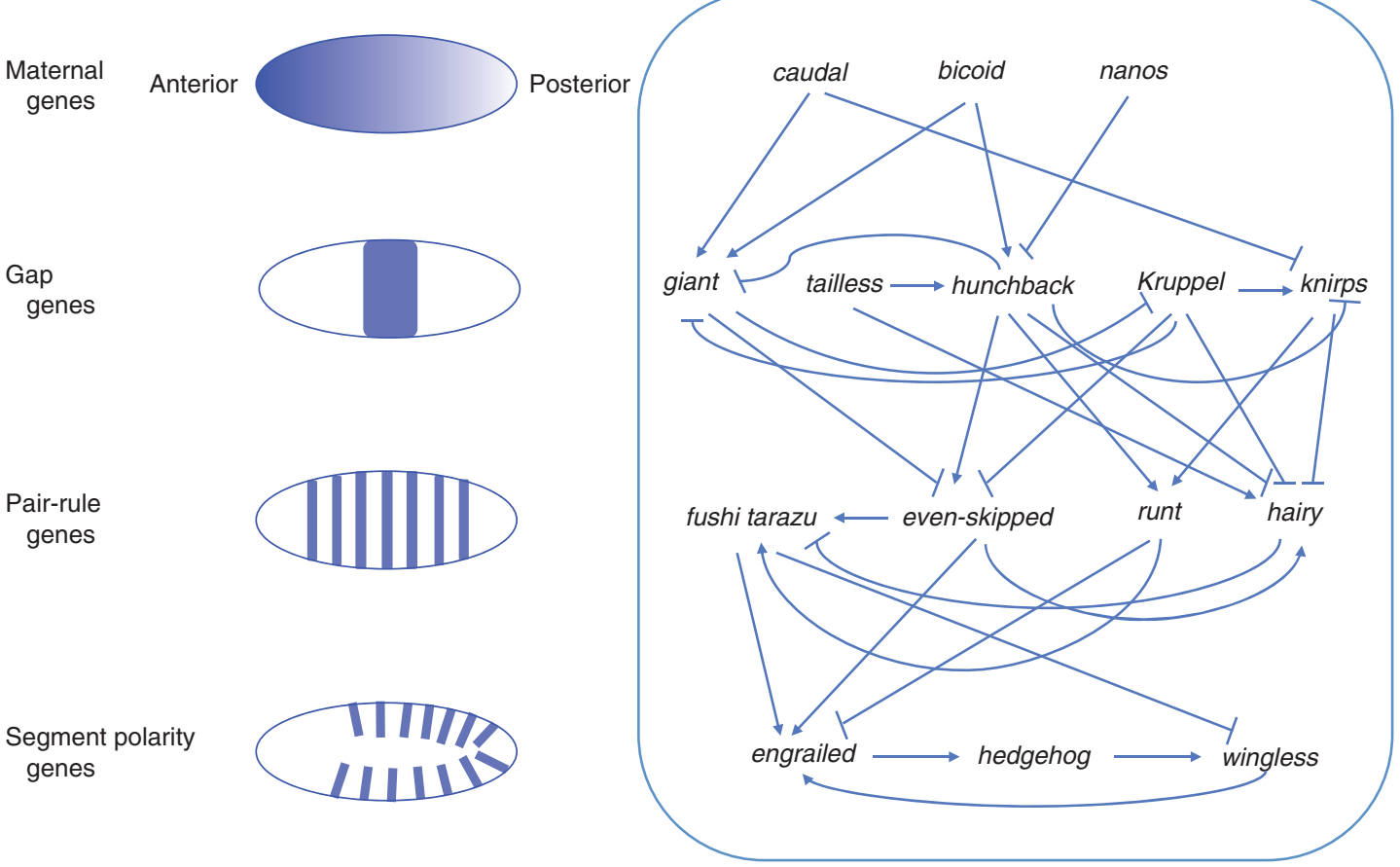

B

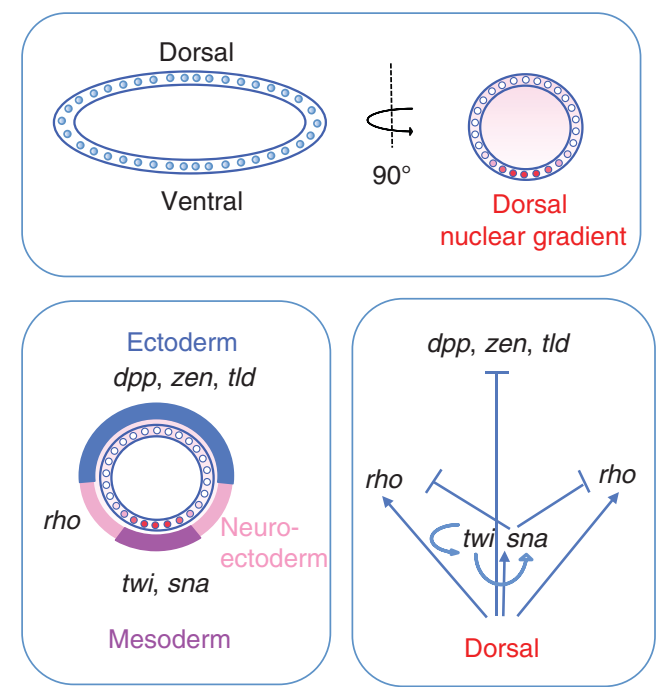

C

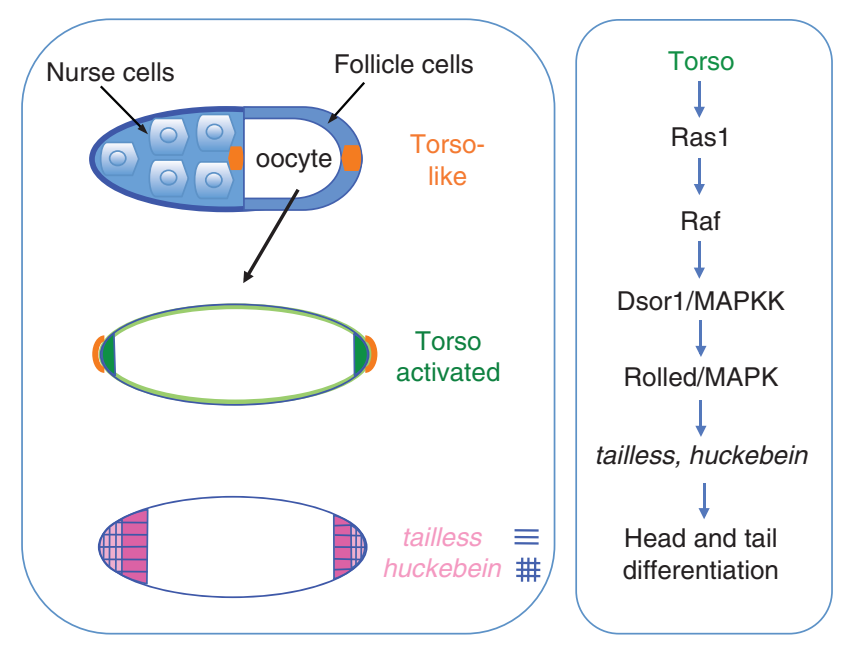

Figure 1. Patterning of the early Drosophila embryo. (A) Anterior-posterior patterning and segmentation of the embryo is initiated by maternally deposited gene products that regulate the expression of gap genes. Gap genes in turn control the expression of pair-rule genes, which themselves regulate segment-polarity genes. The gene hierarchy and activation/repression interactions between different transcription factors that coordinate patterning of the anterior-posterior axis of the early Drosophila embryo are shown to the right. (B) Dorsal-ventral patterning is initiated by a Dorsal nuclear gradient regulated by the Toll/NF- $\kappa \mathrm{B}$ pathway. Graded nuclear localization of Dorsal subdivides the dorso-ventral axis into distinct domains expressing twist (twi) and snail (sna), rhomboid (rho) and decapendaplegic $(d p p)$, zerknullt (zen) and tolloid (tld), which will form the prospective mesoderm, neurogenic ectoderm, and dorsal ectoderm, respectively. Dorsal activates the zygotic transcription program in the dorsoventral axis. $(C)$ Terminal patterning is initiated in the germline by the localized expression of Torsolike in the space outside the poles of the embryo. Torsolike activates the Torso ligand (Trunk) locally and this is followed by Torso activation at the poles of the embryo, which will lead to induction of the terminal patterning genes tailless and huckebein. Torso is an RTK and its action is propagated through the MAPK pathway. 
in response to Dorsal signaling, Twist is activated to define the mesoderm and in turn activates MEF2 and Tinman in different cells to induce the skeletal muscle and cardiac muscle fates, respectively (Fig. 2A) (Sandmann et al. 2007). Another example of progressive specification owing to hierarchical expression of transcription factors and activity of signaling pathways is the specification of Drosophila blood cell types (Jung et al. 2005). In the Drosophila hemocyte (blood cell) lineage the blood cell precursors are specified in the embryo by expression of the transcription factors
Serpent (SRP) and Odd paired (ODD) and progressively express Hemese (HE) and activate the RTK PDGF/VEGF receptor (PVR), as well as the cytokine receptor Dome, to finally reach the prohemocyte stage. Then, cell-type-specific transcription factors are activated in response to signaling by the Notch, PVR or Notch and JAK/STAT pathways, which specify the different populations of mature hemocytes, namely, the plasmatocytes, the crystal cells, and lamellocytes, respectively, that are destined to perform specialized functions (Fig. 2B).

A

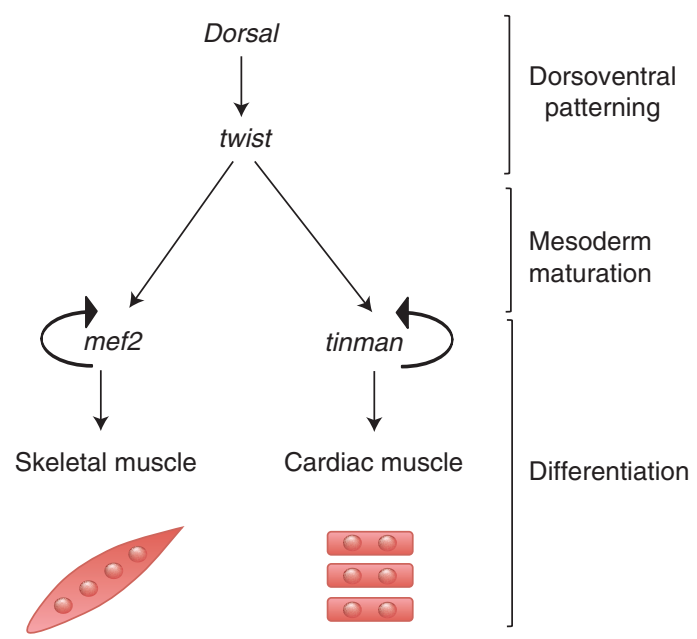

B

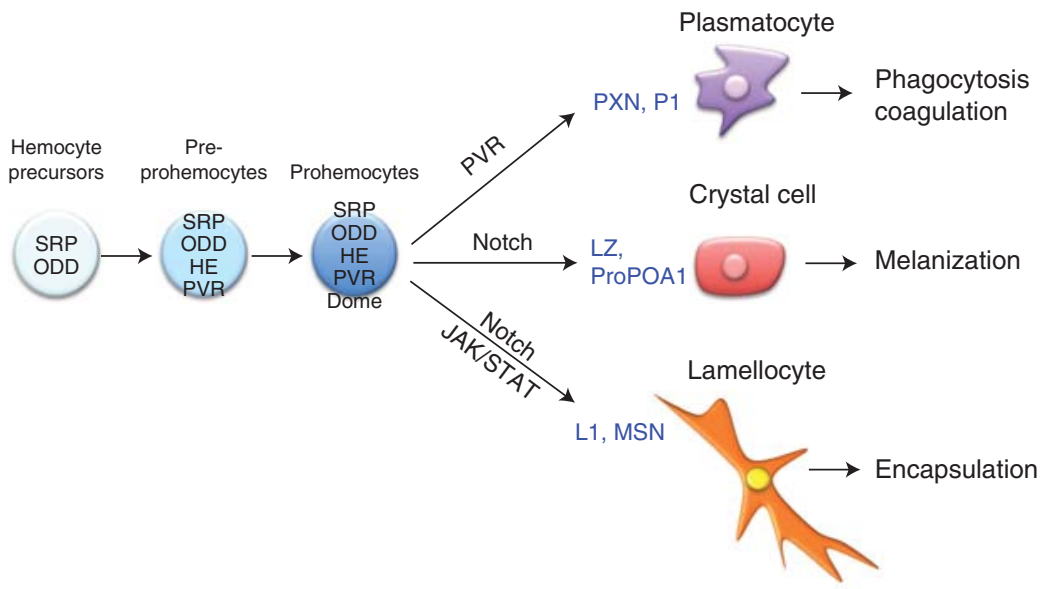

Figure 2. Cell-fate hierarchies in the mesodermal lineage. (A) Muscle cell differentiation. Muscle progenitors are specified in the embryonic mesoderm by Dorsal and activation of the transcription factor Twist. Further subdivision of Twist-positive cells to skeletal and cardiac muscle lineages depends on the expression of the transcription factors MEF2 and Tinman, respectively. (B) Hemocyte maturation in the Drosophila lymph gland. The earliest lymph gland cells, the hemocyte precursors, express SRP and ODD. As these cells transition into preprohemocyte fate, they initiate the expression of HE and PVR. Prohemocytes initiate Dome expression. Maturation to the various hemocyte fates requires down-regulation of Dome, up-regulation of different maturation markers, and the involvement of the indicated signaling pathways. Srp, Serpent; ODD, Odd Skipped; He, Hemese; PVR, PDGF/VEGF receptor; Dome, Domeless; PXN, Peroxidasin; P1, P1 antigen; LZ, Lozenge; ProPOA1, Prophenoloxidase A1; L1, L1 antigen; MSN, Misshapen. 
N. Perrimon et al.

\section{JUXTACRINE SIGNALING: NOTCH AS AN EXAMPLE}

The Notch signaling pathway is a highly conserved mechanism for cell communication between adjacent cells. Both the receptor Notch and its ligands, which belong to the Delta/Serrate/Lag2 (DSL) family, are transmembrane proteins. The requirement for direct cell-cell contact between the signal-sending and signal-receiving cells is necessitated by the membrane-anchored nature of the ligands. Interestingly, studies of the specification of sensory organs in the Drosophila thorax indicate that in some instances DSL ligands can activate Notch signaling beyond directly adjacent cells, because the signal-sending Delta cells extend filopodia that can reach cells a few cell diameters away (de Joussineau et al. 2003; Cohen et al. 2010).

Notch signaling is a simple linear pathway with no amplification step. Interaction of Notch receptors with DSL ligands presented by neighboring cells triggers two proteolytic cleavages within the receptor. The first one is extramembrane, executed by ADAM-family metalloproteases; this generates the substrate for the second cleavage, which is intramembrane, secretase-dependent (like amyloid generation), and releases the intracellular domain of Notch (NICD). NICD is subsequently transported to the nucleus and acts as a transcriptional coactivator that associates with a member of the CSL DNA-binding transcription factor family and turns on target gene expression. Among the targets of the NICD-CSL complex are the E(spl)/HES family genes, which are transcriptional repressors and account for many of the downstream effects of the pathway (reviews by Artavanis-Tsakonas et al. 1999; Bray 2006).

Notch signaling regulates a broad range of cellular processes in organisms ranging from sea urchins to humans, including cell-fate specification, formation of growth-organizing boundaries, stem cell maintenance, proliferation, apoptosis, and migration. Therefore, it is not surprising that its dysfunction has been implicated in many heritable developmental diseases, including Allagille and CADASIL syndromes, as well as cancer, where it promotes tumor growth in some contexts but can prevent it in others. How Notch signaling, especially considering the simplicity of the pathway, specifies so many different biological outcomes, depending on the cell context, is a major question in the field (reviews by Artavanis-Tsakonas et al. 1999; Lai 2004; Fortini 2009). Below we provide just a few examples of developmental processes regulated by different Notch modes of action: lateral inhibition, lineage decisions, and inductive signaling.

One of the best-characterized roles of Notch signaling is lateral inhibition, in which a specific cell fate is defined for a single cell within a group of equivalent cells (Fig. 3). For example, in the Drosophila embryonic neuroepithelium, equivalent ectodermal cells differentiate into either neuroblasts or epithelial cells through the action of Notch signaling. Initially, all neuroepithelial cells express low levels of both the Delta ligand and the Notch receptor. However, probably as the result of stochastic variations, some cells begin to express higher levels of Delta. These small differences are amplified through a positive feedback loop that activates its transcription. Because the cells expressing high levels of the ligand cannot activate signaling because of cisinhibitory interactions with the receptor (Heitzler and Simpson 1993), the system quickly resolves into Delta-expressing signal-sending cells and signal-receiving cells with low Delta levels that activate Notch signaling, which differentiate into neuronal and epithelial cells, respectively. This Notch-dependent lateral inhibition mechanism is used widely in development to pattern tissues containing initially identical cells. The same mechanism is used to select myoblast founder cells in the mesoderm (Bate and Rushton 1993; Rushton et al. 1995) and R8 photoreceptor fate from neural preclusters during eye development (review by Roignant and Treisman 2009). Another well-characterized example of lateral inhibition between two cells is the AC/VU (anchor cell/ventral uterine precursor cell) decision in Caenorhabditis elegans vulva, which is induced by activation of the Notch ortholog Lin 12 that specifies the VU fate (reviews by Greenwald and Rubin 1992; Greenwald 1998).

Notch signaling also operates in control of lineage decisions and inductive signaling between nonequivalent cells. In these cases, the cells are initially distinct from each other either because they asymmetrically express regulators of the Notch pathway or because the ligand and receptor are differentially distributed in adjacent cells (review by Bray 2006). For instance, asymmetric segregation of Numb, which down-regulates Notch signaling through polarized receptor-mediated endocytosis, in the progeny of sensory organ precursors (SOPs) makes the Numb-positive cell Notch sending (Jan and Jan 1995). In contrast, during wing vein specification in Drosophila, expression of Delta in the vein regions induces Notch signaling in the intervein cells to inhibit vein fate, and patterning is established through a positive feedback loop (Huppert et al. 1997). Often a combination of these mechanisms can account for the developmental outcomes. For example, in the Drosophila wing disc, both restricted expression of the glycosyltransferase Fringe, which increases the ability of Notch to bind to Delta, as well as restricted expression of ligands, lead to the specification of the wing margin (Panin et al. 1997).

As a rule of thumb, Notch represents a signaling modality that provides an on/off switch. How is this switch modulated and how is precise signaling ensured? First, multiple levels of regulation of both the receptor and 
A

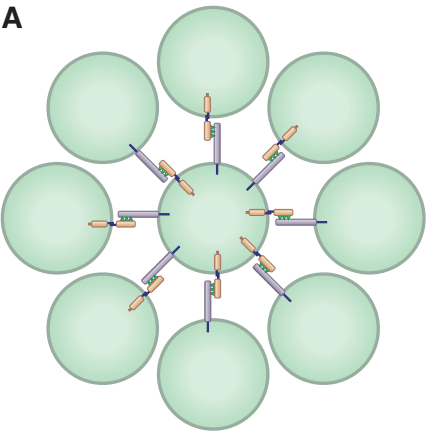

1. Field of equivalent cells that express ligand and receptor

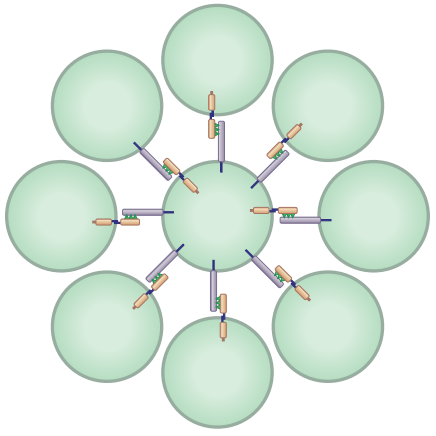

2. Asymmetry due to stochastic changes in ligand expression

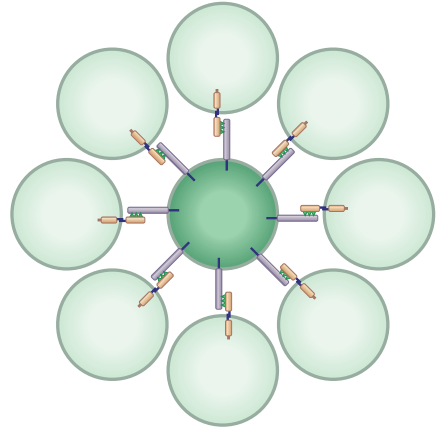

3. Asymmetry establishment and lateral inhibition
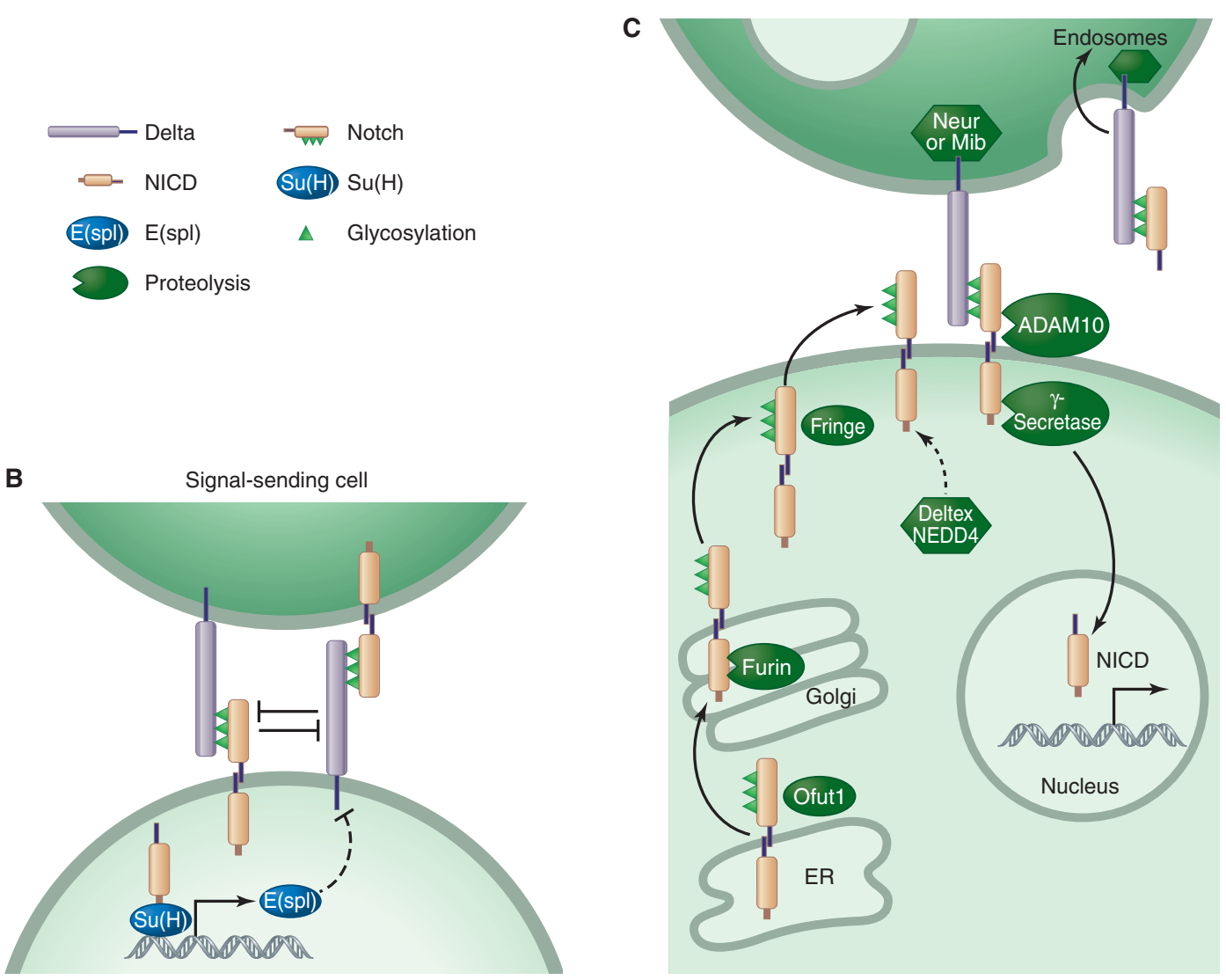

Signal-receiving cell

Figure 3. Lateral inhibition. (A) The process is progressive and can be separated in three steps: (1) Initially, all cells in the cluster express both Delta and Notch and are equivalent. (2) Stochastic changes in gene expression change the balance of ligand and receptor molecules, such that the cell in the middle expresses more Delta. (3) Asymmetry is established when Delta expression in the middle cell is stabilized through a positive feedback loop, resulting in lateral inhibition whereby the Delta-expressing cell becomes the signal sender whereas its neighbors activate Notch signaling and adopt the receiving-cell fate. $(B)$ During Drosophila neurogenesis the cell that activates Delta in the proneural cluster becomes a neuroblast, whereas its neighbors will be laterally inhibited and adopt an epidermal cell fate. The asymmetry between the neighboring cells is established by a negative feedback loop that inhibits Delta in the signal-receiving cell mediated by repressors of the $\mathrm{E}(\mathrm{spl})$ complex. In addition, cis-inhibitory interactions between Notch and Delta exist and contribute to asymmetry generation and lateral inhibition. $(C)$ The Notch receptor and its ligands are subject to a number of protein modifications, such as glycosylation (Ofutl and Fringe), proteolysis (Furin, ADAM10, and $\gamma$-Secreatase), and ubiquitylation (Deltex plus $\mathrm{NEDD}_{4}$ ). These events are critical for maturation of the receptor and its presentation on the cell membrane, for Notch activation on ligand binding, degradation, and trafficking of ligand-receptor complexes. 
ligands are deployed. These include posttranslational modifications such as ubiquitylation that leads to proteasomal degradation, glycosylation, and phosphorylation, as well as trafficking into specific cellular compartments (Shilo and Schejter 2011). Second, when the pathway is used iteratively with a specific duration (e.g., Drosophila and vertebrate neurogenesis and vertebrate somitogenesis), then oscillatory activation/termination mechanisms are utilized. This is achieved not only because the NICD is a very short-lived transcription cofactor, but also because the pathway targets, the HES/E(spl) family, have very unstable messenger RNAs (mRNAs) and proteins, and exert autoinhibitory effects on their own transcription (reviewed by Fior and Henrique 2009).

\section{PATTERNING BY SECRETED PARACRINE FACTORS}

In the case of signaling pathways that are triggered by secreted ligands, a different set of rules applies. First and foremost, the range of signaling elicited by the ligand-producing cell can span tens of cell diameters. Different ligands have diverse distribution ranges, which are used in distinct contexts. The distribution of ligands over a distance of several cell diameters generates a graded signaling profile, which is used in many cases to generate several distinct responses, rather than a single on/off switch.

The observation that a single diffusible molecule could specify and pattern different cell fates in a concentrationdependent manner led to the concept of morphogen gradients (Turing 1952; Wolpert 1969; Meinhardt 1978). Morphogen gradients provide spatial information and generate different cell types in a distinct spatial order. The concentration gradient of the diffusing morphogen subdivides a field of cells by inducing or maintaining the expression of different target genes at distinct concentration thresholds. Accordingly, cells close to the morphogen source receive high levels of morphogen and express both low- and high-threshold target genes. Cells far from the source of the morphogen receive low levels of morphogen and express only lowthreshold target genes. As a result, distinct cell types emerge.

The physical properties of the ligand, as well as its diffusion capacity, mode of transport, endocytosis, and interactions with heparan-sulfate proteoglycans (HSPGs), all affect the final distribution of the ligand and hence the resulting signaling profile. A clear hierarchy of ranges is evident in paracrine signaling in Drosophila tissues. In the case of RTK ligands, including Spitz (which activates the Drosophila EGF receptor), Branchless (which triggers the Drosophila FGF receptor Breathless), and the ligands that activate the Drosophila FGF receptor Heartless, the signaling range is restricted to a small number of cell diameters, typically two to eight. HH displays a similarly limited range. In contrast, the ligands for the BMP and $\mathrm{Wnt} / \mathrm{Wg}$ pathways have a longer range, which can extend up to 30 cell diameters. Interestingly, as discussed below, lipid modifications of both $\mathrm{HH}$ and Wnts are important for distribution of these molecules in tissues. Below, we provide several examples illustrating the mechanisms underlying the regulation of ligand distribution for each of these major signaling pathways.

\section{CONTROLLING THE SIGNALING RANGE OF SECRETED FACTORS}

\subsection{EGF and FGF}

The range of EGFR signaling in Drosophila is regulated primarily by the amount of secreted ligand provided to the receiving cells. Three of the four EGFR ligands (Spitz, Keren, and Gurken) are produced as inactive transmembrane precursors that are sequestered in the endoplasmic reticulum (ER). The fourth ligand, Vein, is produced from the outset as a secreted molecule. Trafficking of ligand to a secretory compartment where processing takes place is facilitated by a transmembrane chaperone named Star (Lee et al. 2001; Tsruya et al. 2002). Within the secretory compartment, cleavage of the precursor is performed by intramembrane proteases of the Rhomboid family, and the cleaved extracellular ligand portion is subsequently secreted (Urban et al. 2001). The chaperone Star is also cleaved by Rhomboid proteins but this cleavage generates an inactive molecule (Tsruya et al. 2007). Some of the Rhomboid proteins localize not only to the secretory compartment but also to the ER. When Star encounters Rhomboid in the ER, it is inactivated before it can promote trafficking of the ligand precursors to the secretory compartment where ligand cleavage should take place (Yogev et al. 2008). Thus, only a fraction of the chaperone molecules escape inactivating cleavage in the ER, and hence the level of ligand precursor that is trafficked and secreted is significantly reduced. This leads to a corresponding reduction in the range of signaling. In tissues where a restricted range of EGFR activation is required, such as the eye disc or the germline, Rhomboid proteins are present in both the ER and secretory compartment.

Once ligand is secreted, another tier of regulation is used. High levels of EGFR activation induce the expression of the target gene argos, which encodes a secreted molecule that neutralizes the ligand (Golembo et al. 1996; Klein et al. 2004). Induction of Argos thus reduces the levels of active ligand that can diffuse from the source, and hence the range of signaling.

In responding cells, additional mechanisms restrict the signaling range, functioning in a cell-autonomous manner. Two inhibitor-encoding genes (kekkon1 [Ghiglione et al. 
1999] and sprouty [Casci et al. 1999; Kramer et al. 1999; Reich et al. 1999]), in particular, are induced in a classical negative-feedback loop. In both cases, the induction of the inhibitors in a fairly broad range of the receiving cells results in productive signaling only in cells that are closer to the ligand source, and receive enough input to overcome the inhibitory effects. Kekkon 1 encodes a transmembrane protein that generates inactive heterodimers with EGFR. Sprouty is an inhibitor of ERK/MAPK signaling whose mechanism of inhibition of RTK signaling remains incompletely understood. It interacts with several proteins impinging on signaling, including Grb2, Raf, Cbl, and PP2A, and undergoes phosphorylation that alters its binding properties and stability (Edwin et al. 2009; Reddi et al. 2010). Because Sprouty operates downstream from the receptor, by interacting with components common to multiple RTK pathways, it attenuates signaling by both FGF- and EGF-induced pathways (Hacohen et al. 1998). Both Kekkon1 and Sprouty are conserved in vertebrates. Sprouty, in particular, is an essential component that modulates RTK pathways in normal development and disease (Edwin et al. 2009).

The transcriptional output of RTK signaling is mediated by members of the ETS family of transcription factors. Most prominent is the ETS-domain protein Pointed, which has two isoforms generated by alternative splicing (Klambt 1993; O'Neill et al. 1994). ERK activates each of the two forms in a different manner. Phosphorylation of PointedP2 converts an inactive protein to the active form. The mechanistic basis for activation by phosphorylation is not known but may involve stabilization, nuclear translocation, and exposure of the transcriptional activation or DNAbinding domains. The second isoform, PointedP1, is constitutively active even in the absence of ERK signaling. However, its expression is dependent on ERK activity (Gabay et al. 1996). The transcription factor that responds to ERK activity to trigger PointedP1 expression is not known.

The YAN protein contains an ETS DNA-binding domain but is devoid of a transcriptional activation domain. YAN is also a target for ERK phosphorylation, but in this case phosphorylation leads to its inactivation by promoting nuclear exit and degradation (Rebay and Rubin 1995). The dual and opposite effects of ERK on the activators and inhibitor may make the induction of ETS-target genes more robust (Fig. 4).

An interesting variation occurs in the case of the Breathless FGF receptor. The receptor itself restricts diffusion of the ligand Branchless. The role of Breathless is to guide migration of tracheal cells toward the ligand source. To increase the sharpness of the attracting ligand gradient, expression of the receptor is induced by high levels of signaling, generating a trap that restricts the diffusion of the Branchless ligand (Oshiro et al. 2002).

\subsection{Hedgehog}

HH transmits information over several cell diameters, but its range is restricted. The distribution of $\mathrm{HH}$ has been studied most intensively in the wing imaginal disc, where it defines a zone of activation in the boundary between the posterior and anterior compartments of the disc. All posterior cells produce $\mathrm{HH}$ but do not respond to it, whereas the anterior cells do not produce it but can respond to it (review by Ingham and McMahon 2001). The range of HH diffusion from the posterior compartment determines the signaling range, and the region of the anterior compartment that receives $\mathrm{HH}$ subsequently becomes the domain that produces the BMP family ligand DPP, which directs long-range patterning of the wing.

$\mathrm{HH}$ is unusual as it undergoes dual lipid modification and autoproteolytic cleavage (Porter et al. 1996; Pepinsky et al. 1998; Chen et al. 2004). The cholesterol moiety that is added limits $\mathrm{HH}$ trafficking within and between cells and palmitoylation is required for the production of a soluble multimeric $\mathrm{HH}$ protein. Binding of $\mathrm{HH}$ to its receptor Patched (PTC) leads to its endocytosis and degradation. Because PTC functions by inhibiting the next step in the pathway (the transmembrane protein Smoothened [SMO]), this leads to pathway activation. Interestingly, $p t c$ itself is a transcriptional target gene for $\mathrm{HH}$ signaling (reviewed in Wilson and Chuang 2010). As in the case of Branchless, this leads to more effective trapping of $\mathrm{HH}$ by the first rows of cells receiving the signal, and hence to a restriction of the signaling range.

Recently, studies in mammalian cells have shown that mammalian Hh signaling depends on the primary cilium, a small cellular projection found on most vertebrate cells (Goetz et al. 2009). In particular, Smo proteins participate in the transduction of Hh signals, moving into the cilium in response to Hh ligand. Interestingly, the absence of cilia in Drosophila suggests that a fundamental difference exists between the organization of the Hh pathway between invertebrates and mammals.

\subsection{BMPs/TGF $\beta$ and Wnt/Wg Ligands}

The BMP and Wnt/Wg family ligands act over a long range, especially in the wing disc, to pattern not only the cells close to the ligand source but also those positioned many cell diameters away. In these cases the regulation is more intricate as it involves shaping the distribution of the ligand over a long range, restricting signaling close to the source while facilitating signaling further away. This is important for maintaining the robustness of the resulting gradient to changes in the level of ligand produced (Eldar et al. 2003). 
N. Perrimon et al.

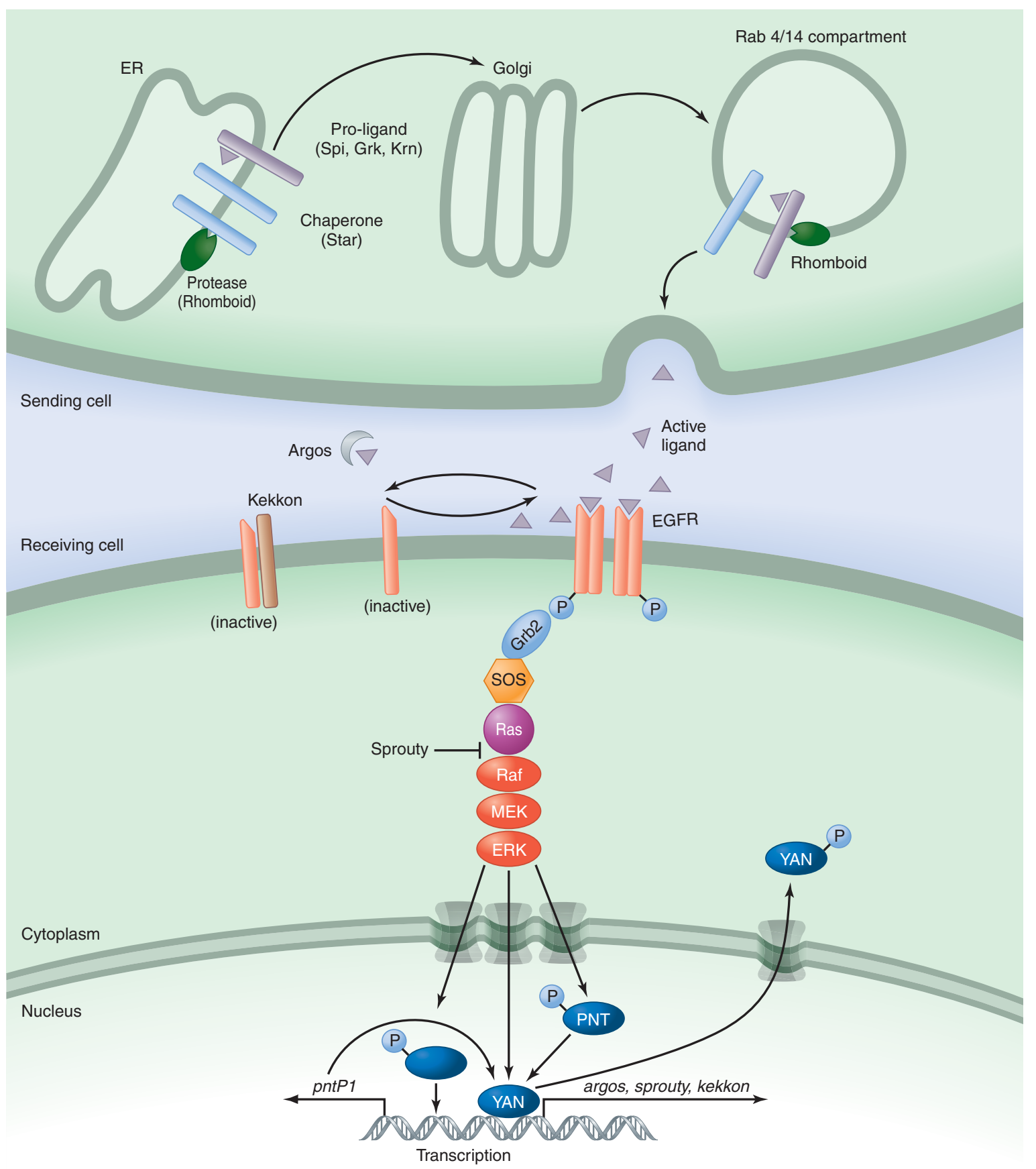

Figure 4. The EGFR pathway in Drosophila. Three membrane-anchored ligands—Spitz (SPI), Gurken (GRK), and Keren (KRN) - are retained in the ER, and are processed following trafficking by the chaperone protein Star, which is dedicated to these molecules, to the Rab4/14 compartment in the secretory pathway. In this compartment, the ligands encounter Rhomboid proteins, seven-transmembrane-span intramembrane serine proteases, which cleave the ligand precursors within the transmembrane domain, to release the active, secreted form. Rhomboids also reside in the ER cleave and inactivate Star, thus attenuating the level of ligand precursor that is trafficked to the Rab4/14 compartment. Within the receiving cells, the ligands encounter the EGF receptor, which on dimerization triggers the canonical SOS/Ras/Raf/MEK/MAPK pathway. The cardinal transcriptional output of the pathway is mediated by the ETS protein Pointed (PNT). In addition, the ETS protein YAN provides a constitutive repressor, which competes for Pointed binding sites, and can be removed from the nucleus and degraded upon phosphorylation by ERK. Several negative regulators keep the pathway in check. Especially important is a group of inducible repressive elements, which constitute a negative-feedback loop. Argos is a secreted molecule, which sequesters the ligand SPI, whereas Sprouty and Kekkon1 attenuate signaling within the receiving cell. 
As in the case of Hh signaling, signaling by BMP regulates the expression level of the receptors; however, in this case the expression of the BMP receptor is inhibited by signaling (Lecuit et al. 1996). This generates a situation where less ligand trapping takes place close to the source, facilitating long-range diffusion. In addition, the elevated receptor levels further from the source make these cells more responsive to the low levels of ligand they encounter. Finally, the induction of inhibitors that block intracellular signaling, such as DAD (Tsuneizumi et al. 1997), which competes with the Smad proteins that transduce BMP signals, further restricts signaling close to the ligand source. The range of this response is dictated by the sensitivity of the promoter/enhancer of the inhibitory molecules to induction by signaling.

Another set of extracellular molecules that shape the distribution of BMPs and Wnts/Wg are HSPGs, which comprise a transmembrane protein core and long chains of sugars that emanate from this core (Perrimon and Bernfield 2000). The versatility of covalent links that can be formed between the sugar molecules has the potential to generate enormous complexity and hence specificity. Although the association between the ligands and HSPGs represents a low-affinity interaction, the sheer number of HSPGs may compensate for this low affinity. It is estimated that the number of HSPG molecules per cell is at least two orders of magnitude higher than that of the specific ligand receptors. Hence, the ligands travel in a "forest" of HSPGs, where they rarely encounter their specific receptors. HSPGs can have opposing effects on activation, and hence analysis of their function is complicated. They may facilitate signaling locally by trapping ligands and functioning as coreceptors that present the ligand to receptors such as FGFR. However, they may also facilitate signaling at a distance by either stabilizing the ligand or functioning as long-range carriers after cleavage of their extracellular protein stem. This latter activity also reduces the level of signaling close to the ligand source (reviewed in Yan and Lin 2009).

$\mathrm{Wnt} / \mathrm{Wg}$ proteins, in addition to interacting with HSPGs, are modified by palmitoylation, a hydrophobic modification on a conserved cysteine residue that affects their distribution, as well as a second lipid modification by palmitoleic acid esterification of a serine residue. Studies in Drosophila and vertebrates have provided evidence that Wnt palmitoylation is controlled by Porcupine, predicted to be a membrane-bound $\mathrm{O}$-acyl transferase, and that this modification is important for the generation of Wnt gradients. In Drosophila lack of palmitoylation in porcupine mutants affects WG secretion (Kadowaki et al. 1996). Similarly, in the chick neural tube porcupine-mediated lipid modification reduces the range of activity of Wnt1 and Wnt3a (Gali et al. 2007).

\subsection{Long-Range Ligand Distribution}

Studies of DPP and Wnt signaling in cell clones, in which the receptor is eliminated or a constitutively active receptor is expressed, have shown that the original signals are transmitted even to the most distant cells (Lecuit and Cohen 1996; Nellen and Basler 1996; Neumann and Cohen 1997), rather than being relayed by inducing secondary signals. Several models have been proposed for the long-range distribution of ligands, which may use multiple strategies. Although all of the proposed models are supported by several lines of compelling evidence, critical experiments directly eliminating one mode of trafficking and monitoring the outcome have not been performed for technical reasons. We therefore present the prevailing models below.

The simplest mechanism for ligand distribution is diffusion in the extracellular milieu. Reduction in ligand levels over a distance may be driven by endocytosis or extracellular degradation. HSPGs may enhance or reduce diffusion and keep the ligand in the plane of the epithelium by low-affinity interactions (Strigini and Cohen 2000). The association of some ligands with hydrophobic moieties, most notably $\mathrm{Hh}$ and cholesterol and palmitoylate, as well as Wnt/Wg proteins and palmitoylate, have raised the possibility of another mode of extracellular ligand trafficking, in which membrane fragments bearing these named argosomes are dispersed over large distances (Greco et al. 2001; Panáková et al. 2005). Exovesicles like these have been characterized in Drosophila imaginal discs. They contain Wnt/Wg proteins, are derived from basolateral membranes, and travel through tissues, where they are found predominantly in endosomes.

Another option is transcytosis of the ligand. In this scenario the ligand travels most of its journey in vesicles within cells. Its dilution over a distance is affected by the fraction of ligand that is endocytosed and by efficiency of ligand transfer between cells versus its intracellular degradation. Experiments have shown that elimination of the receptor in a group of cells adjacent to the ligand source reduces signaling in more distant cells that have a normal receptor. This suggests that the receptor is required in the proximal cells for incorporating the ligand into the cells and transferring it distally (reviewed in Wartlik and Gonzalez-Gaitan 2009).

One of the most provocative suggestions for the transfer of ligands over tens of cell diameters involves very thin cellular protrusions termed cytonemes. These have been proposed to serve as conduits in which morphogens move between producing and target cells (reviewed in Kornberg and Guha 2007). These structures have been identified in the epithelium of the wing disc and point toward cells that produce ligands. They contain the relevant ligand receptors, and their polarity is disrupted by uniform presentation of the respective ligand (Roy et al. 2011). Cytonemes have been 
N. Perrimon et al.

proposed to serve to traffic the ligand to the cell body where signaling may take place. Interestingly, cytonemes are also found in vertebrate cells and thus may play a general role in long-range cell-cell communication.

\section{THE LOGIC OF SIGNALING}

Although pathways use distinct signaling components and signaling strategies, a number of common universal themes have emerged regarding their structures and regulation in time and space.

\subsection{Linear Signaling Pathways}

Developmental signaling elicited by ligand-receptor binding appears to be transmitted in a linear fashion within the cell, leading to induction of target genes. This is very different from typical signaling schemes in which multiple converging and diverging links are observed. The most compelling evidence for such linearity is that mutations in different components along a pathway give rise to very similar phenotypes (reviewed by Friedman and Perrimon 2007). This linearity of developmental signaling stems from the need to transmit a clear signal, in view of the irreversibility of the resulting decisions. This holds true both for cases where an on/off switch is induced and for situations where graded signaling elicits diverse responses, according to the level of signaling. Each pathway regulates the activity of one or more transcription factors, which bind to specific signaling pathway response elements in the enhancers and promoters of target genes (Barolo and Posakony 2002).

\subsection{Negative Feedback Switches}

Tight regulation of signaling is essential for generation of reproducible patterns during development. In the case of pathways that function as switches that induce a particular cell fate within a zone of competent cells, this will determine the spatial boundaries of signaling. For ligands that function as morphogens to induce several distinct cell fates, this regulation will determine the overall spatial profile of resulting patterns. Another important consideration in signaling is the need to buffer against noise stemming from heterozygosity, unequal distribution of components between dividing cells and environmental fluctuations. Negative feedback provides a way of fine-tuning the signal over a range of signaling levels and sharpening boundaries between regions that respond differently.

Many examples of transcriptional induction of negative regulators exist. In some cases, these regulators function extracellularly to restrict the level or distribution of active ligand. For example, Noggin inhibits TGF $\beta$ signaling by binding to TGF $\beta$ family ligands and preventing them from binding to their receptors (Smith 1999). Similarly, the Argos molecule binds to EGFR ligands, thus effectively reducing their levels (Klein et al. 2004). In other cases, the inhibitor induced is acting only in the receiving cells. Examples of transmembrane molecules that compromise receptor activity include Kekkon1, which inhibits EGFR (Ghiglione et al. 1999). Inducible molecules that interfere with signaling intracellularly include Sprouty, which is a general repressor of ERK kinase signaling (Casci et al. 1999; Kramer et al. 1999; Reich et al. 1999), Dad, which competes with Smad proteins (Tsuneizumi et al. 1997), and axin, which negatively regulates $\mathrm{Wnt} / \mathrm{Wg}$ signaling (Ikeda et al. 1998). For the cell-autonomous inhibitors, a relatively broad range of induction by signaling is required, such that only the cells that receive a signal above a certain threshold level experience productive signaling.

\subsection{Generating a Threshold}

In the case of Notch signaling, in which the ligand is membrane anchored, the boundaries of signaling are dictated by the contact zones between the sending and receiving cells. However, in cases where the ligand is diffusible, a graded signaling profile will be generated. Regardless of the range, this graded activation pattern is converted to sharp borders of induction of gene expression.

The underlying mechanisms for generating transcriptional thresholds are crucial for proper patterning. Several mechanisms have been identified. During early dorsoventral patterning in the Drosophila embryo, graded nuclear localization of the transcription factor Dorsal (an NF- $\mathrm{B}$ homolog) is converted to sharp borders of zygotic gene expression (e.g., twist and snail in the ventralmost cells, which define the future mesoderm). The snail regulatory region contains multiple adjacent binding sites for Dorsal. Binding of one Dorsal molecule to DNA may facilitate the binding of additional molecules by protein - protein interactions, generating a sharper response (Rusch and Levine 1996).

In the case of BMP target genes in the wing disc, different stringencies of regulation may apply depending on the position of the responding cell relative to the ligand source. Of particular interest is the potential transcription factor Brinker (BRK), which negatively regulates DPP target genes in both the Drosophila wing disc and embryo. BRK antagonizes transcription of target genes, and forms a gradient that opposes the BMP activation gradient. Genes that are expressed closer to the ligand source require simultaneous suppression of brk expression and activation of transcription by Smads (along with binding of accessory transcription factors). For genes that are expressed in a broader pattern and hence require lower signaling levels for their 
induction, suppression of brk expression is sufficient (Affolter and Basler 2007).

Finally, a mechanism for generating transcriptional thresholds termed zero-order hypersensitivity has been proposed. In cases where a transcription factor, or transcriptional repressor, undergoes reversible phosphorylation and is in excess, even small differences in the rates of the reversible phosphorylation and dephosphorylation reactions will lead to the complete accumulation of the protein in one form or another. This generates a sharp threshold response (Melen et al. 2005).

\section{INTEGRATING SIGNALING PATHWAYS}

Many of the mechanisms underlying cell-type specification and formation of distinct tissues rely on interactions between signaling pathways. Often the activation of one pathway leads to activation of a second, the two pathways acting in a sequential or relay mode. In addition, two signaling pathways can act in parallel and converge to regulate the activity of the same target. Finally, cross talk can result from "pathway interference," in which one pathway modulates the activity of a canonical component of another.

A striking example of how the spatial and temporal interaction of signaling pathways can produce complex patterns during development is somitogenesis, the process that generates the spine through the periodic establishment of the embryonic segments from the paraxial mesoderm in vertebrates (Dequeant and Pourquie 2008). Somites are masses of mesoderm distributed along the two sides of the neural tube that give rise to the dermis, skeletal muscles, and vertebrae. During somitogenesis an oscillating mechanism, called the segmentation clock, drives pulses of expression of a limited number of genes repeatedly in the presomitic mesoderm (PSM) every time a new somite is formed. The first evidence that cyclic gene expression drives somitogenesis came from the observation that the HES1 (Hairy and Enhancer of split 1) mRNA is expressed in a dynamic cyclic pattern coinciding with the formation of each somite (Fig. $5 \mathrm{~A})$. Subsequently, several other genes with similar cyclic behavior were identified, the vast majority of which have been shown to be components of the Notch, FGFR, and Wnt signaling pathways (Fig. 5B). In particular, in the mouse, Notch-FGF-regulated genes oscillate out of phase with Wnt-regulated genes and their activation in the PSM is mutually exclusive. This suggests tight, coordinated regulation of signaling (Dequeant et al. 2006), which is achieved by a large number of negative-feedback loops (Fig. 5B) and the presence of a pacemaker that triggers the rhythmic coordinated activation of these signaling pathways.

FGF and Wnt signaling are regulated temporally and spatially. The ligands are expressed in gradients in the precursor tissue of the segments where they regulate the progressive maturation/differentiation of the tissue and define the domain of the clock activities. The Wnt pathway, for example, is activated in the PSM before segmentation, plays a role upstream of both the Wnt and Notch oscillations, and is thought to entrain the Notch feedback loop. As a result, the spatial and highly dynamic temporal regulations of these signaling activities guarantee the robust segmentation patterning of the vertebrate axis and are evolutionarily conserved in vertebrates (Dequeant and Pourquie 2008). In addition, experiments in zebrafish have indicated that the Notch pathway is required for synchrony of the oscillations at the cellular level and the coordinated expression of the correct targets within neighboring cells, because lack of Notch leads to a "salt and pepper" pattern of oscillations (Fig. 5A) (Dequeant and Pourquie 2008).

Determination of mesodermal progenitors in the Drosophila embryo (Carmena et al. 1998) exemplifies the complex interplay and integration of signaling pathways at the promoter level (Fig. 6). Using the regulation of the evenskipped (eve) promoter, Halfon et al. (2000) have illustrated how the synergistic integration of transcription factors, regulated by the Wnt/Wg, DPP/BMP, and EGF/FGF/ ERK pathways, generates a specific developmental transcriptional response at a single defined enhancer. Because some of the pathways are activated earlier than others and in a broader domain, they determine the "competence group" of cells (expressing markers like Lethal of scute, L'sc) and lead to subsequent activation of additional pathways within a more restricted cell population (Fig. 6A) These later pathways are regarded as inductive, and it is the final integration of the transcriptional signals from all pathways, within a single enhancer, that induces the relevant target gene. In this system, the WG and DPP signals are orthogonal to each other and define the intersection zone as the competence group, through signal-responsive transcription factors (MAD and TCF) that induce two tissuespecific transcription factors (Tinman and Twist). In addition, TCF also contributes to the expression of essential elements for ERK signaling (i.e., Rhomboid, Heartless, and Heartbroken). Once activated, ERK provides the inductive signal, by activating the transcription factor Pointed and inactivating the YAN repressor (Fig. 6B). Finally, singling out of mesodermal Eve progenitors is achieved through the process of lateral inhibition mediated by Notch/Delta signaling (Carmena et al. 2002).

Such integration of signaling pathways at the promoter/enhancer level allows each gene to define its "rules" of regulation, according to the tissue setting in which it is activated. Two given pathways can act synergistically in one setting and antagonistically in another. Thus, whereas only a small number of signaling pathways are used during 
N. Perrimon et al.
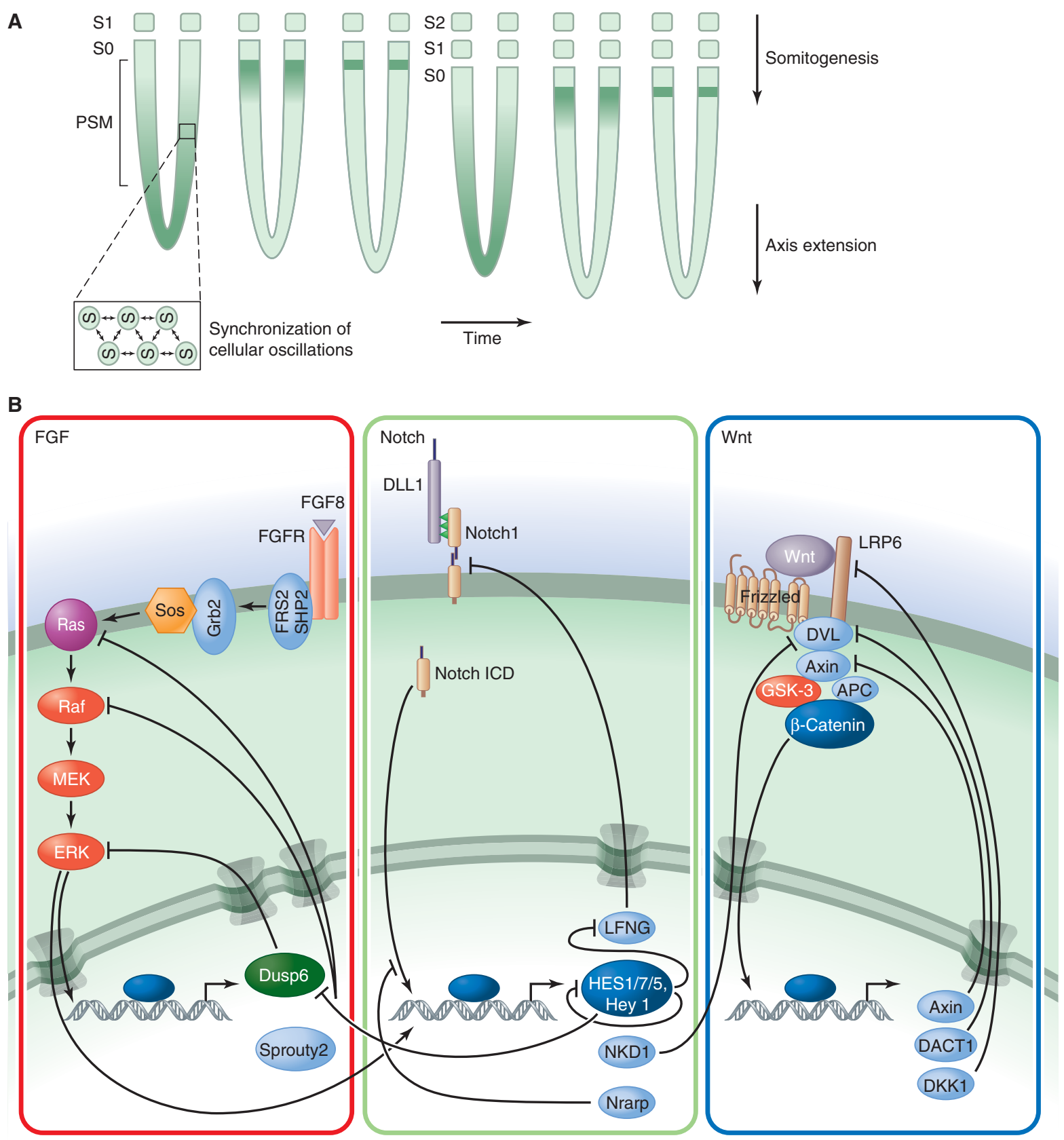

Figure 5. The segmentation clock oscillator. (A) Evidence of an oscillator underlying vertebrate segmentation comes from the transcriptional expression of the hairyl gene (dark green) in periodic waves in the presomitic mesoderm (PSM). These waves are associated with the timely formation of pairs of somites that are added sequentially. Experiments in zebrafish have shown that a remarkable property among neighboring PSM cells is that they undergo synchronized gene-expression oscillations (as shown in boxed area), which are coordinated by the Notch signaling pathway. (B) The FGF, Notch, and Wnt signaling pathways underlie the mouse oscillator. Cyclic genes belonging to the FGF (left) and Notch (middle) pathways oscillate in opposite phase to cyclic genes of the Wnt pathway (right). Several feedback loops are indicated. These are involved in reinforcing activity or shutting down a pathway. Some instances of pathway crosstalk have also been observed. APC, adenomatous polyposis coli; DACT1, dapper homolog 1; DKK1, dickkopf homolog 1; FGFR, fibroblast growth factor receptor; Grb2, growth factor receptor bound protein; Dll1, Delta-like 1; DSH, dishevelled; DUSP6, dual specificity phosphatase 6; ERK, mitogen-activated protein kinase 1; GSK3, glycogen synthase kinase 3; HES, hairy enhancer of split-related; LFng, lunatic fringe; LPR6, low-density lipoprotein receptor-related protein 6; MEK, mitogen-activated protein kinase 1; NICD, Notch intracellular domain; NKD1, naked cuticle 1 homolog; Nrarp, Notch-regulated ankyrin repeat protein; SHP2, Src homology region 2-containing protein tyrosine phosphatase 2; SOS, son of sevenless. 


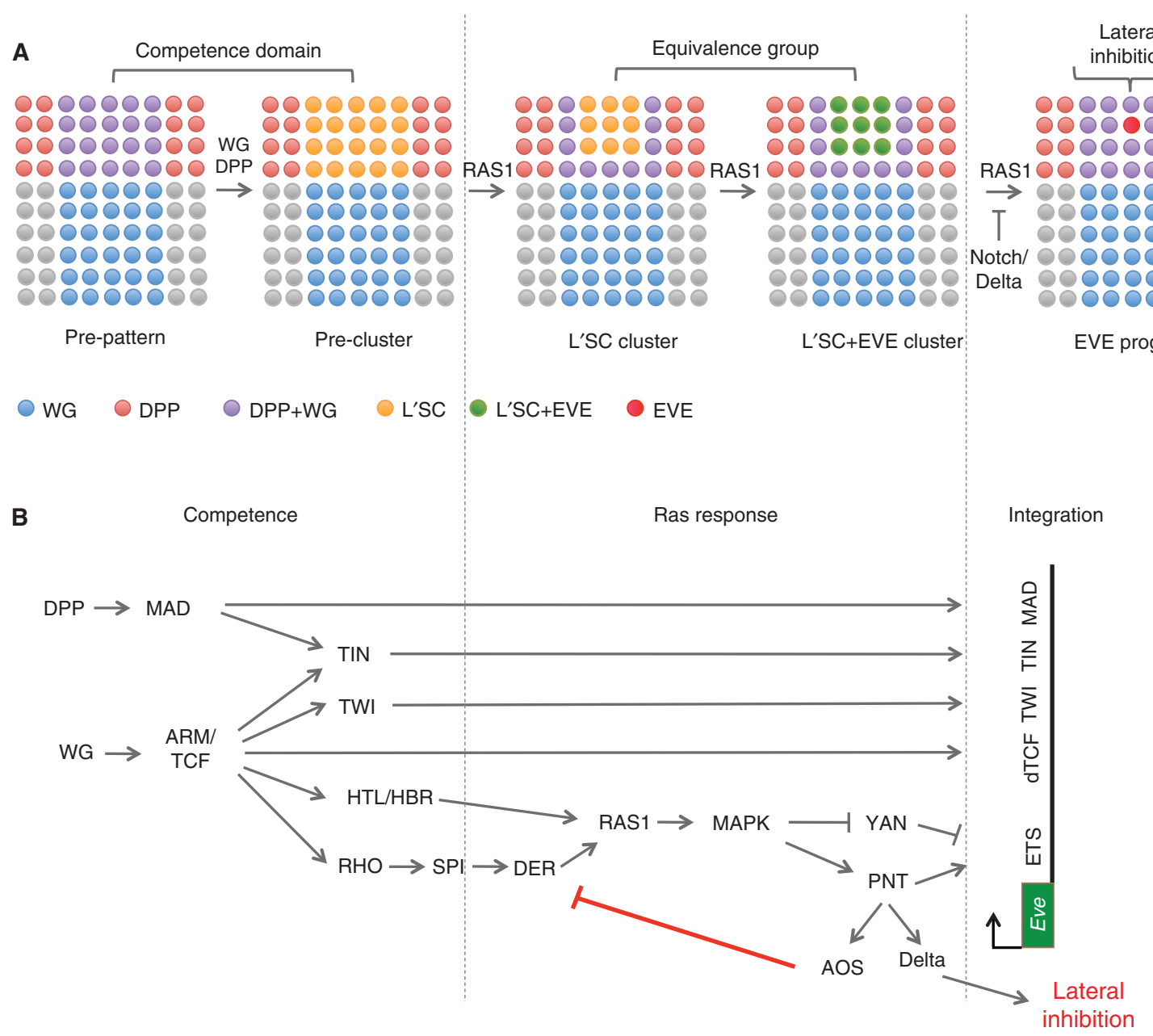

Figure 6. The WG/DPP/FGF interplay during specification of Drosophila mesodermal progenitors. (A) A model for patterning of the embryonic Drosophila mesoderm through the combinatorial actions of WG, DPP, and RAS/ERK signals. This model applies to both somatic muscle and pericardial muscle. The intersection between WG (red) and DPP (blue) delineates a prepattern (purple) in which Lethal of scute (L'SC) is initially activated in a precluster (orange). The entire L'SC precluster is competent to respond to RAS1. However, the spatially restricted activation of Heartless (HTL) and EGFR restricts L'SC to a subset of precluster cells that correspond to an equivalence group. RAS1 signaling activates EVE expression in all cells of the L'sc cluster (green) and subsequently a single EVEexpressing progenitor (red) is determined by lateral inhibition mediated by the Notch/Delta pathway. $(B)$ WG, DPP, and RAS1 signal integration during specification of mesodermal EVE progenitors. WG and DPP provide developmental competence by regulating tissue-specific transcription factors (Tinman [TIN] and Twist [TWI]), signal-responsive transcription factors (MAD, TCF), and proximal components of the RTK/ERK pathway (FGFR/ HTL, Heartbroken [HBR]/DOF and Rhomboid [RHO]). The RAS pathway leads to activation of the ETS-binding transcription factor Pointed (PNT) and inactivation of the ETS-binding YAN repressor. The activities of all five transcriptional activators (TIN, TWI, MAD, TCF, and PNT) are integrated at the MHE (Muscle and Heart Enhancer) of eve, which is located $6 \mathrm{~kb}$ downstream from its transcription start site, and synergistically promote eve expression. In the absence of inductive RAS signaling, YAN represses eve by binding to ETS sites. In addition, RAS/ PNT signaling in the EVE progenitor promotes Delta and Argos (AOS) expression, which in combination activate Notch and shut down EGFR signaling in the nonprogenitor cells, to ensure lateral inhibition.

development, the combinatorial flexibility at the promoter level generates a vast array of possible responses. This would not be possible if more stringent and hardwired interactions between pathways operated more broadly at the cytoplasmic level.
Studies of cell-fate specification in the Drosophila eye have illustrated how two pathways, EGFR and Notch, can be utilized both sequentially and in parallel (Flores et al. 2000). Specifically, cone cell differentiation, visualized by the expression of the transcription factor PAX2, requires 
N. Perrimon et al.

inputs from the EGFR and Notch pathways by neighboring $\mathrm{R}$ photoreceptor cells that produce both EGF and Delta ligands. In addition, the expression of the Delta ligand in $\mathrm{R}$ photoreceptor cells requires high levels of EGFR signaling (Flores et al. 2000; Tsuda et al. 2002; see reviews by Nagaraj and Banerjee 2004; Doroquez and Rebay 2006). Interestingly, differentiation of the R7 photoreceptor cell requires input from another RTK, Sevenless (SEV), activated by the transmembrane protein Bride of Sevenless (BOSS) (Perrimon and Perkins 1997).

Finally, a number of pathway interference mechanisms operating upstream of transcription have been documented. For example, studies in mammals and Drosophila have identified a mechanism by which the Hippo pathway coordinates Wnt/Wg morphogenetic signaling with growth control. Signaling via the Hippo pathway is critical for the precise control of organ size. Activation of the Hippo serine/threonine kinase leads to inhibition of the transcriptional coactivator TAZ and YAP (also known as Yorkie [YKI] in Drosophila) through phosphorylation and nuclear exclusion dependent on binding to 14-3-3 proteins. Varelas et al. (2010) showed that the Hippo pathway restricts Wnt/ $\beta$-catenin signaling by promoting interactions between TAZ and Dishevelled, a cytoplasmic component of the canonical Wnt/Wg pathway. Similarly, Xia et al. (2010) have reported that the Fused (FU) serine/threonine kinase, a component of the canonical Hh pathway, functions together with the E3 ligase Smurf to regulate the ubiquitylation and subsequent degradation of Thick veins (TKV), a BMP receptor, during oogenesis. This mechanism ensures the generation of a steep gradient of BMP activity between the germline stem cell and its progeny. The degradation of TKV then permits expression of differentiation genes in the daughter cell.

Such examples may represent special cases rather than the norm in the context of developmental processes. Indeed, as stated above, during developmental signaling, cytoplasmic cross talk between pathways appears to be kept to a minimum to ensure that cells integrate signals quickly and effectively (Noselli and Perrimon 2000). An example of the simplicity more commonly seen is ERK regulation during Drosophila embryogenesis. When the active form of MAPK is monitored immunohistochemically, for every pattern that is observed, a single RTK has been shown to be responsible (Gabay et al. 1997). This reveals the striking absence of overlaps between RTK pathways in time and space.

\section{CONCLUDING REMARKS: DEVELOPMENTAL VERSUS PHYSIOLOGICAL SIGNALING}

In addition to their developmental roles, the signaling pathways discussed here play central roles in animal physiology. However, in contrast to their roles in development, where they act in ratchetlike mechanisms pushing forward developmental programs by regulating the activity of transcription factors, in physiological contexts the pathways are used to gauge the environment and fine-tune the physiological state of the cell, and as such are reversible.

\section{ACKNOWLEDGMENTS}

We thank Mary-Lee Dequeant for helpful comments. Work in the Perrimon laboratory is supported by the Howard Hughes Medical Institute and NIH, and work in the Shilo laboratory by a grant from the Minerva Foundation.

\section{REFERENCES}

* Reference is also in this collection.

Affolter M, Basler K. 2007. The decapentaplegic morphogen gradient: From pattern formation to growth regulation. Nat Rev Genet 8: $663-674$

Arbouzova NI, Zeidler MP. 2006. JAK/STAT signalling in Drosophila: Insights into conserved regulatory and cellular functions. Development 133: $2605-2616$.

Artavanis-Tsakonas S, Rand MD, Lake RJ. 1999. Notch signaling: Cell fate control and signal integration in development. Science 284: 770-776.

Barolo S, Posakony JW. 2002. Three habits of highly effective signaling pathways: Principles of transcriptional control by developmental cell signaling. Genes Dev 16: 1167-1181.

Bate M, Rushton E. 1993. Myogenesis and muscle patterning in Drosophila. C R Acad Sci III 316: 1047-1061.

Bray SJ. 2006. Notch signalling: A simple pathway becomes complex. Nat Rev Mol Cell Biol 7: 678-689.

Carmena A, Gisselbrecht S, Harrison J, Jimenez F, Michelson AM. 1998. Combinatorial signaling codes for the progressive determination of cell fates in the Drosophila embryonic mesoderm. Genes Dev 12: 3910-3922.

Carmena A, Buff E, Halfon MS, Gisselbrecht S, Jimenez F, Baylies MK, Michelson AM. 2002. Reciprocal regulatory interactions between the Notch and Ras signaling pathways in the Drosophila embryonic mesoderm. Dev Biol 244: 226-242.

Casci T, Vinos J, Freeman M. 1999. Sprouty, an intracellular inhibitor of Ras signaling. Cell 96: 655-665.

Chen MH, Li YJ, Kawakami T, Xu SM, Chuang PT. 2004. Palmitoylation is required for the production of a soluble multimeric Hedgehog protein complex and long-range signaling in vertebrates. Genes Dev 18: $641-659$.

Cohen M, Georgiou M, Stevenson NL, Miodownik M, Baum B. 2010. Dynamic filopodia transmit intermittent Delta-Notch signaling to drive pattern refinement during lateral inhibition. Dev Cell 19: 78-89.

De Joussineau C, Soule J, Martin M, Anguille C, Montcourrier P, Alexandre D. 2003. Delta-promoted filopodia mediate long-range lateral inhibition in Drosophila. Nature 426: 555-559.

Dequeant ML, Pourquie O. 2008. Segmental patterning of the vertebrate embryonic axis. Nat Rev Genet 9: 370-382.

Dequeant ML, Glynn E, Gaudenz K, Wahl M, Chen J, Mushegian A, Pourquie O. 2006. A complex oscillating network of signaling genes underlies the mouse segmentation clock. Science 314: 1595-1598.

Doroquez DB, Rebay I. 2006. Signal integration during development: Mechanisms of EGFR and Notch pathway function and cross-talk. Crit Rev Biochem Mol Biol 41: 339-385.

Duffy JB, Perrimon N. 1994. The torso pathway in Drosophila: Lessons on receptor tyrosine kinase signaling and pattern formation. Dev Biol 166: $380-395$. 
Edwin F, Anderson K, Ying C, Patel TB. 2009. Intermolecular interactions of Sprouty proteins and their implications in development and disease. Mol Pharmacol 76: 679-691.

Eldar A, Rosin D, Shilo BZ, Barkai N. 2003. Self-enhanced ligand degradation underlies robustness of morphogen gradients. Dev Cell 5: $635-646$.

Feng XH, Derynck R. 2005. Specificity and versatility in tgf- $\beta$ signaling through Smads. Annu Rev Cell Dev Biol 21: 659-693.

Fior R, Henrique D. 2009. "Notch-Off": A perspective on the termination of Notch signalling. Int J Dev Biol 53: 1379-1384.

Flores GV, Duan H, Yan H, Nagaraj R, Fu W, Zou Y, Noll M, Banerjee U. 2000. Combinatorial signaling in the specification of unique cell fates. Cell 103: 75-85.

Fortini ME. 2009. Notch signaling: The core pathway and its posttranslational regulation. Dev Cell 16: 633-647.

Freeman M. 2000. Feedback control of intercellular signalling in development. Nature 408: 313-319.

Friedman A, Perrimon N. 2007. Genetic screening for signal transduction in the era of network biology. Cell 128: 225-231.

Gabay L, Scholz H, Golembo M, Klaes A, Shilo BZ, Klambt C. 1996. EGF receptor signaling induces pointed $\mathrm{P} 1$ transcription and inactivates Yan protein in the Drosophila embryonic ventral ectoderm. Development 122: 3355-3362.

Gabay L, Seger R, Shilo BZ. 1997. MAP kinase in situ activation atlas during Drosophila embryogenesis. Development 124: 3535-3541.

Galli LM, Barnes TL, Secrest SS, Kadowaki T, Burrus LW. 2007. Porcupine-mediated lipid-modification regulates the activity and distribution of Wnt proteins in the chick neural tube. Development 134: $3339-3348$.

Gerhart J. 1999. 1998 Warkany lecture: Signaling pathways in development. Teratology 60: 226-239.

Ghabrial A, Luschnig S, Metzstein MM, Krasnow MA. 2003. Branching morphogenesis of the Drosophila tracheal system. Annu Rev Cell Dev Biol 19: 623-647.

Ghiglione C, Carraway KLIII, Amundadottir LT, Boswell RE, Perrimon N, Duffy JB. 1999. The transmembrane molecule kekkon 1 acts in a feedback loop to negatively regulate the activity of the Drosophila EGF receptor during oogenesis. Cell 96: 847-856.

Gilbert SF. 2000. Developmental biology, 6th ed. Sinauer Associates, Sunderland, MA.

Goetz SC, Ocbina PJ, Anderson KV. 2009. The primary cilium as a Hedgehog signal transduction machine. Methods Cell Biol 94: 199222.

Golembo M, Raz E, Shilo BZ. 1996. The Drosophila embryonic midline is the site of Spitz processing, and induces activation of the EGF receptor in the ventral ectoderm. Development 122: 3363-3370.

Greco V, Hannus M, Eaton S. 2001. Argosomes: A potential vehicle for the spread of morphogens through epithelia. Cell 106: 633-645.

Greenwald I. 1998. LIN-12/Notch signaling: Lessons from worms and flies. Genes Dev 12: 1751-1762.

Greenwald I, Rubin GM. 1992. Making a difference: The role of cell-cell interactions in establishing separate identities for equivalent cells. Cell 68: $271-281$.

Hacohen N, Kramer S, Sutherland D, Hiromi Y, Krasnow MA. 1998. Sprouty encodes a novel antagonist of FGF signaling that patterns apical branching of the Drosophila airways. Cell 92: 253-263.

Halfon MS, Carmena A, Gisselbrecht S, Sackerson CM, Jimenez F, Baylies MK, Michelson AM. 2000. Ras pathway specificity is determined by the integration of multiple signal-activated and tissue-restricted transcription factors. Cell 103: 63-74.

* Harrison DA. 2012. The JAK/STAT pathway. Cold Spring Harb Perspect Biol doi: 10.1101/cshperspect.a011205.

* Hariharan I. 2012. The Hippo pathway. Cold Spring Harb Perspect Biol doi: $10.1101 /$ cshperspect.a011288.
Heemskerk J, DiNardo S, Kostriken R, O’Farrell PH. 1991. Multiple modes of engrailed regulation in the progression towards cell fate determination. Nature 352: 404-410.

Heitzler P, Simpson P. 1993. Altered epidermal growth factor-like sequences provide evidence for a role of Notch as a receptor in cell fate decisions. Development 117: 1113-1123.

Hou SX, Zheng Z, Chen X, Perrimon N. 2002. The Jak/STAT pathway in model organisms: Emerging roles in cell movement. Dev Cell 3: $765-778$.

Huppert SS, Jacobsen TL, Muskavitch MA. 1997. Feedback regulation is central to $\Delta$-Notch signalling required for Drosophila wing vein morphogenesis. Development 124: 3283-3291.

Ikeda S, Kishida S, Yamamoto H, Murai H, Koyama S, Kikuchi A. 1998. Axin, a negative regulator of the Wnt signaling pathway, forms a complex with GSK- $3 \beta$ and $\beta$-catenin and promotes GSK-3 $\beta$-dependent phosphorylation of $\beta$-catenin. EMBO J 17: 1371-1384.

* Ingham P. 2012. Hedgehog signaling. Cold Spring Harb Perspect Biol doi: $10.1101 /$ cshperspect.a011221.

Ingham PW, McMahon AP. 2001. Hedgehog signaling in animal development: Paradigms and principles. Genes Dev 15: 3059-3087.

Jan YN, Jan LY. 1995. Maggot's hair and bug's eye: Role of cell interactions and intrinsic factors in cell fate specification. Neuron 14: 1-5.

Jiang J, Hui CC. 2008. Hedgehog signaling in development and cancer. Dev Cell 15: 801-812.

Jung SH, Evans CJ, Uemura C, Banerjee U. 2005. The Drosophila lymph gland as a developmental model of hematopoiesis. Development 132: $2521-2533$

Kadowaki T, Wilder E, Klingensmith J, Zachary K, Perrimon N. 1996. The segment polarity gene porcupine encodes a putative multitransmembrane protein involved in Wingless processing. Genes Dev 10: $3116-3128$

Klambt C. 1993. The Drosophila gene pointed encodes two ETS-like proteins which are involved in the development of the midline glial cells. Development 117: 163-176.

Klein DE, Nappi VM, Reeves GT, Shvartsman SY, Lemmon MA. 2004. Argos inhibits epidermal growth factor receptor signalling by ligand sequestration. Nature 430: 1040-1044.

* Kopan R. 2012. Notch pathway. Cold Spring Harb Perspect Biol doi: 10.1101/cshperspect.a011213.

Kornberg TB, Guha A. 2007. Understanding morphogen gradients: A problem of dispersion and containment. Curr Opin Genet Dev 17: 264-271.

Kramer S, Okabe M, Hacohen N, Krasnow MA, Hiromi Y. 1999. Sprouty: A common antagonist of FGF and EGF signaling pathways in Drosophila. Development 126: 2515-2525.

Lai EC. 2004. Notch signaling: Control of cell communication and cell fate. Development 131: 965-973.

Lecuit T, Brook WJ, Ng M, Calleja M, Sun H, Cohen SM. 1996. Two distinct mechanisms for long-range patterning by Decapentaplegic in the Drosophila wing. Nature 381: 387-393.

Lee JR, Urban S, Garvey CF, Freeman M. 2001. Regulated intracellular ligand transport and proteolysis control EGF signal activation in Drosophila. Cell 107: 161-171.

Levine M. 2008. Dorsal-ventral patterning of the Drosophila embryo. In The legacy of Drosophila genetics: From "defining the gene" to "analyzing genome function" (ed. Bier E). Henry Stewart Talks, London.

Logan CY, Nusse R. 2004. The Wnt signaling pathway in development and disease. Annu Rev Cell Dev Biol 20: 781-810.

MacDonald BT, Tamai K, He X. 2009. Wnt/ $\beta$-catenin signaling: Components, mechanisms, and diseases. Dev Cell 17: 9-26.

Meinhardt H. 1978. Space-dependent cell determination under the control of morphogen gradient. J Theor Biol 74: 307-321.

Melen GJ, Levy S, Barkai N, Shilo BZ. 2005. Threshold responses to morphogen gradients by zero-order ultrasensitivity. Mol Syst Biol 1: 2005.0028 . 
N. Perrimon et al.

Nagaraj R, Banerjee U. 2004. The little R cell that could. Int J Dev Biol 48: $755-760$.

Nellen D, Burke R, Struhl G, Basler K. 1996. Direct and long-range action of a DPP morphogen gradient. Cell 85: 357-368.

Neumann CJ, Cohen SM. 1997. Long-range action of Wingless organizes the dorsal-ventral axis of the Drosophila wing. Development 124: $871-880$.

Noselli S, Perrimon N. 2000. Signal transduction. Are there close encounters between signaling pathways? Science 290: 68-69.

* Nusse R. 2012. Wnt signaling. Cold Spring Harb Perspect Biol doi: 10.1101/cshperspect.a011163.

Nusslein-Volhard C, Wieschaus E. 1980. Mutations affecting segment number and polarity in Drosophila. Nature 287: 795-801.

O’Neill EM, Rebay I, Tjian R, Rubin GM. 1994. The activities of two Etsrelated transcription factors required for Drosophila eye development are modulated by the Ras/MAPK pathway. Cell 78: 137-147.

Ohshiro T, Emori Y, Saigo K. 2002. Ligand-dependent activation of breathless FGF receptor gene in Drosophila developing trachea. Mech Dev 114: 3-11.

Pan D. 2007. Hippo signaling in organ size control. Genes Dev 21: 886-897.

Panakova D, Sprong H, Marois E, Thiele C, Eaton S. 2005. Lipoprotein particles are required for Hedgehog and Wingless signalling. Nature 435: 58-65.

Panin VM, Papayannopoulos V, Wilson R, Irvine KD. 1997. Fringe modulates Notch-ligand interactions. Nature 387: 908-912.

Pepinsky RB, Zeng C, Wen D, Rayhorn P, Baker DP, Williams KP, Bixler SA, Ambrose CM, Garber EA, Miatkowski K, et al. 1998. Identification of a palmitic acid-modified form of human Sonic hedgehog. J Biol Chem 273: 14037-14045.

Perrimon N, Bernfield M. 2000. Specificities of heparan sulphate proteoglycans in developmental processes. Nature 404: 725-728.

Perrimon N, McMahon AP. 1999. Negative feedback mechanisms and their roles during pattern formation. Cell 97: 13-16.

Perrimon N, Perkins L. 1997. There must be 50 ways to rule the signal: The case of the Drosophila EGF receptor. Cell 89: 13-16.

Porter JA, Ekker SC, Park WJ, von Kessler DP, Young KE, Chen CH, Ma Y, Woods AS, Cotter RJ, Koonin EV, et al. 1996. Hedgehog patterning activity: Role of a lipophilic modification mediated by the carboxyterminal autoprocessing domain. Cell 86: 21-34.

Pownall ME, Isaacs HV. 2010. FGF signalling in vertebrate development. Morgan \& Claypool Life Sciences, San Rafael, CA.

Rebay I, Rubin GM. 1995. Yan functions as a general inhibitor of differentiation and is negatively regulated by activation of the Ras1/MAPK pathway. Cell 81: 857-866.

Reddi HV, Madde P, Marlow LA, Copland JA, McIver B, Grebe SK, Eberhardt NL. 2010. Expression of the PAX8/PPAR $\gamma$ fusion protein is associated with decreased neovascularization in vivo: Impact on tumorigenesis and disease prognosis. Genes Cancer 1: 480-492.

Reich A, Sapir A, Shilo B. 1999. Sprouty is a general inhibitor of receptor tyrosine kinase signaling. Development 126: 4139-4147.

Roignant JY, Treisman JE. 2009. Pattern formation in the Drosophila eye disc. Int J Dev Biol 53: 795-804.

Roy S, Hsiung F, Kornberg TB. 2011. Specificity of Drosophila cytonemes for distinct signaling pathways. Science 332: 354-358.

Rusch J, Levine M. 1996. Threshold responses to the dorsal regulatory gradient and the subdivision of primary tissue territories in the Drosophila embryo. Curr Opin Genet Dev 6: 416-423.

Rushton E, Drysdale R, Abmayr SM, Michelson AM, Bate M. 1995. Mutations in a novel gene, myoblast city, provide evidence in support of the founder cell hypothesis for Drosophila muscle development. Development 121: 1979-1988.

Sandmann T, Girardot C, Brehme M, Tongprasit W, Stolc V, Furlong EE. 2007. A core transcriptional network for early mesoderm development in Drosophila melanogaster. Genes Dev 21: 436-449.

Saucedo LJ, Edgar BA. 2007. Filling out the Hippo pathway. Nat Rev Mol Cell Biol 8: 613-621.

Shilo BZ. 2005. Regulating the dynamics of EGF receptor signaling in space and time. Development 132: 4017-4027.

Shilo BZ, Schejter ED. 2011. Regulation of developmental intercellular signalling by intracellular trafficking. EMBO J 30: 3516-3526.

Smith WC. 1999. TGF $\beta$ inhibitors. New and unexpected requirements in vertebrate development. Trends Genet 15: 3-5.

Spemann H, Mangold H. 1924. Über induktion von Embryonalagen durch Implantation Artfremder Organisatoren. Roux' Arch Entw Mech 100: 599-638.

St Johnston D, Nusslein-Volhard C. 1992. The origin of pattern and polarity in the Drosophila embryo. Cell 68: 201-219.

Strigini M, Cohen SM. 2000. Wingless gradient formation in the Drosophila wing. Curr Biol 10: 293-300.

Tsruya R, Schlesinger A, Reich A, Gabay L, Sapir A, Shilo BZ. 2002. Intracellular trafficking by Star regulates cleavage of the Drosophila EGF receptor ligand Spitz. Genes Dev 16: 222-234.

Tsruya R, Wojtalla A, Carmon S, Yogev S, Reich A, Bibi E, Merdes G, Schejter E, Shilo BZ. 2007. Rhomboid cleaves Star to regulate the levels of secreted Spitz. EMBO J 26: 1211-1220.

Tsuda L, Nagaraj R, Zipursky SL, Banerjee U. 2002. An EGFR/Ebi/Sno pathway promotes $\delta$ expression by inactivating $\mathrm{Su}(\mathrm{H}) /$ SMRTER repression during inductive notch signaling. Cell 110: 625-637.

Tsuneizumi K, Nakayama T, Kamoshida Y, Kornberg TB, Christian JL, Tabata T. 1997. Daughters against dpp modulates dpp organizing activity in Drosophila wing development. Nature 389: 627-631.

Turing AM. 1952. The chemical basis of morphogenesis. Philos Trans $R$ Soc London B 237: 37-72.

Urban S, Lee JR, Freeman M. 2001. Drosophila rhomboid-1 defines a family of putative intramembrane serine proteases. Cell 107: 173-182.

Varelas X, Miller BW, Sopko R, Song S, Gregorieff A, Fellouse FA, Sakuma R, Pawson T, Hunziker W, McNeill H, et al. 2010. The Hippo pathway regulates Wnt/ $\beta$-catenin signaling. Dev Cell 18: 579-591.

Waddington CH. 1940. Organizers and genes. Cambridge University Press, Cambridge.

Wartlick O, Kicheva A, Gonzalez-Gaitan M. 2009. Morphogen gradient formation. Cold Spring Harb Perspect Biol 1: a001255.

Wilson CW, Chuang PT. 2010. Mechanism and evolution of cytosolic Hedgehog signal transduction. Development 137: 2079-2094.

Wolpert L. 1969. Positional information and the spatial pattern of cellular differentiation. $J$ Theor Biol 25: 1-47.

* Wrana JL. 2012. TGF-beta/Smad pathway. Cold Spring Harb Perspect Biol doi: $10.1101 /$ cshperspect.a011197.

Wu MY, Hill CS. 2009. Tgf- $\beta$ superfamily signaling in embryonic development and homeostasis. Dev Cell 16: 329-343.

Xia L, Jia S, Huang S, Wang H, Zhu Y, Mu Y, Kan L, Zheng W, Wu D, Li X, et al. 2010. The Fused/Smurf complex controls the fate of Drosophila germline stem cells by generating a gradient BMP response. Cell 143: 978-990.

Yan D, Lin X. 2009. Shaping morphogen gradients by proteoglycans. Cold Spring Harb Perspect Biol 1: a002493.

Yogev S, Schejter ED, Shilo BZ. 2008. Drosophila EGFR signalling is modulated by differential compartmentalization of Rhomboid intramembrane proteases. EMBO J 27: 1219-1230. 


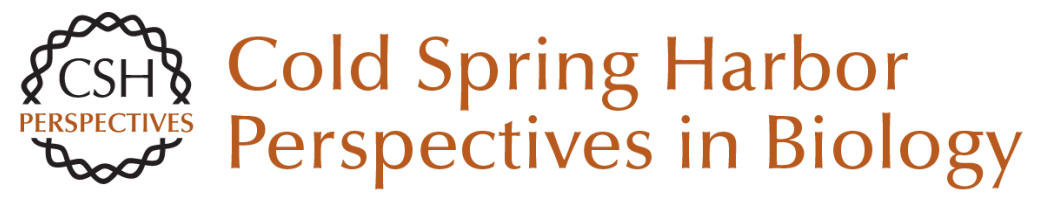

\section{Signaling Mechanisms Controlling Cell Fate and Embryonic Patterning}

Norbert Perrimon, Chrysoula Pitsouli and Ben-Zion Shilo

Cold Spring Harb Perspect Biol 2012; doi: 10.1101/cshperspect.a005975

Subject Collection Signal Transduction

Cell Signaling and Stress Responses Gökhan S. Hotamisligil and Roger J. Davis

Protein Regulation in Signal Transduction Michael J. Lee and Michael B. Yaffe

Synaptic Signaling in Learning and Memory Mary B. Kennedy

Vertebrate Reproduction Sally Kornbluth and Rafael Fissore

Signaling in Lymphocyte Activation Doreen Cantrell

Signaling in Muscle Contraction Ivana Y. Kuo and Barbara E. Ehrlich

Toll-Like Receptor Signaling Kian-Huat Lim and Louis M. Staudt

Signaling Pathways that Regulate Cell Division Nicholas Rhind and Paul Russell
Second Messengers

Alexandra C. Newton, Martin D. Bootman and John D. Scott

Signals and Receptors Carl-Henrik Heldin, Benson Lu, Ron Evans, et al.

Cell Death Signaling Douglas $R$. Green and Fabien Llambi

Signaling Networks that Regulate Cell Migration Peter Devreotes and Alan Rick Horwitz

Signaling Networks: Information Flow, Computation, and Decision Making Evren U. Azeloglu and Ravi lyengar

Signal Transduction: From the Atomic Age to the Post-Genomic Era Jeremy Thorner, Tony Hunter, Lewis C. Cantley, et al.

Signaling by the TGF $\beta$ Superfamily Jeffrey L. Wrana

Subversion of Cell Signaling by Pathogens Neal M. Alto and Kim Orth

For additional articles in this collection, see http://cshperspectives.cshlp.org/cgi/collection/

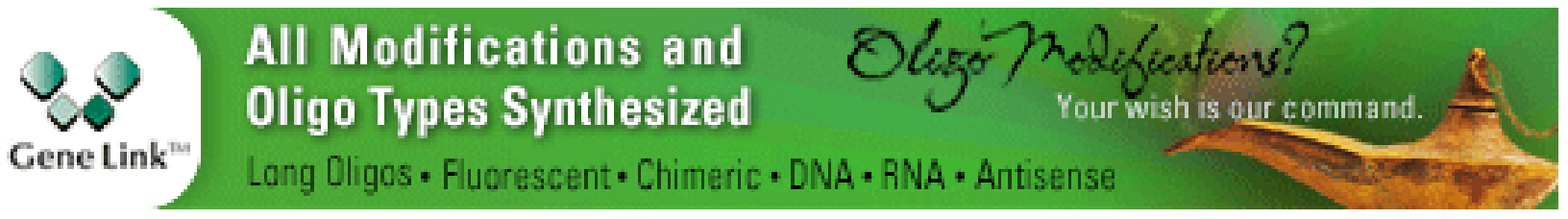

Copyright (C) 2012 Cold Spring Harbor Laboratory Press; all rights reserved 